\title{
How to obtain adequate biopsy specımen in suspected thymic tumors
}

\author{
Semra Bilaçeroğlu \\ University of Health Sciences-Turkey, Izmir Dr. Suat Seren Training and Research Hospital for Thoracic Medicine and Surgery, Izmir, Turkey \\ Correspondence to: Prof. Semra Bilaçeroğlu, MD. 6173 Sokak No: 9 Kardelen Apt. Daire: 22, 35560 Bostanl, Izmir, Turkey. \\ Email: s.bilaceroglu@gmail.com.
}

\begin{abstract}
Pathologic diagnosis of thymic tumors (TTs) can be made by surgical or nonsurgical procedures. About $20 \%$ of TTs had been diagnosed by pretreatment biopsy methods while the rest had gone to surgery for diagnosis and treatment. However, in the last two decades there was an increase in pretreatment procedures for optimal management of locally advanced or metastatic TTs. Pretreatment tissue diagnosis of a noninvasive TT is not a standard option but is required if there is suspect or atypical clinical presentation and imaging, an invasive tumor requiring a nonsurgical approach or preoperative chemotherapy or chemoradiotherapy, strong possibility of lymphoma or unclear differential diagnosis between lymphoma or other solid tumor by imaging studies, or suspicion of a metastatic lesion. In surgical diagnosis anterior mediastinotomy, video-assisted thoracic surgery or mediastinoscopy can be chosen for invasive TTs whereas total resection is performed for small, noninvasive tumors. Nonsurgical diagnosis can be made by transthoracic fine or core needle biopsies (TTFNA, TTCNB), conventional bronchoscopy, endobronchial ultrasonography-guided transbronchial needle aspiration (EBUS-TBNA), endoscopic ultrasound-guided fine needle aspiration (EUS-FNA) or medical thoracoscopy depending on procedural amenability according to tumor extension. TTFNA and TTCNB have been the most frequently used nonsurgical methods. However, there is an upward trend in using conventional bronchoscopy, EBUS-TBNA, EUS-FNA and medical thoracoscopy recently. To increase the diagnostic performance of these procedures in TTs, recommendations are (I) obtaining histologic specimens, (II) combining smears or liquid based cytology preparations and cell blocks, (III) obtaining multiple sufficient samples, (IV) combining histologic and cytologic specimens, (V) performing morphologic, immunohistochemical and molecular analyses on all specimens, (VI) using rapid onsite evaluation for cytologic specimens, (VII) correlating pathologic, clinical and radiologic findings, (VIII) consulting experienced pathologists.
\end{abstract}

Keywords: Thymoma; thymic tumor (TT); diagnosis; biopsy; transthoracic needle biopsy

Submitted Dec 07, 2019. Accepted for publication Mar 23, 2020.

doi: 10.21037/jtd-2019-thym-14

View this article at: http://dx.doi.org/10.21037/jtd-2019-thym-14

\section{Introduction}

Thymoma, a rare neoplasm arising from the thymic epithelial cells, is the most common tumor of the anterior mediastinum accounting for approximately $50 \%$ of anterior and $20 \%$ of all mediastinal masses. The incidence of thymoma is estimated to be $1.5-6.3$ per million (1-3). It can be an asymptomatic incidental finding on chest radiography, or present with signs and symptoms consistent with a local mediastinal disorder or unusual paraneoplastic syndrome. Prognosis in thymoma is generally determined by clinical staging and ability to achieve complete tumor resection rather than histologic classification (4).

Pathologic diagnosis of thymoma and other thymic tumors can be made by surgical methods or nonsurgical biopsy procedures. Owing to their low incidence, there is a paucity of large case series and studies specifically elucidating the adequacy and performance of various 
diagnostic modalities for thymomas or other thymic tumors (4-6). In general, only about $20 \%$ of the thymic tumors are diagnosed by pretreatment biopsy methods while the rest go directly to surgery for diagnosis and treatment. However, in the last two decades there has been a significant increase (from $11.8 \%$ to $18.6 \%$ ) in the use of minimally invasive pretreatment biopsy methods particularly in locally advanced or metastatic thymic tumors for optimal management and outcome $(6,7)$.

\section{Obtaining tissue for histopathologic diagnosis}

Pretreatment tissue diagnosis of thymoma (a noninvasive mediastinal tumor associated with myastenia gravis) by surgical or nonsurgical procedures is not a standard option but it is required when at least one of the situations below is present (7-10):

(I) Suspect or atypical clinical presentation and imaging,

(II) Invasive tumor requiring a non-operative approach or preoperative chemotherapy or chemo-radiotherapy according to the new histological criteria for thymic tumors in the World Health Organization (WHO) classification [differentiation of lymphocyte-rich thymomas (AB, B1, B2) from epithelial-predominant thymomas (A, B3) and thymic carcinomas],

(III) Strong possibility of lymphoma or unclear differential diagnosis between lymphoma or other solid tumor (non-myasthenic thymoma, thymic carcinoma, germ cell tumor, etc.) with imaging studies,

(IV) Suspicion of a metastatic lesion.

However, these surgical or nonsurgical biopsy procedures should not violate the pleural space owing to high possibility of pleural dissemination in thymic tumors (8). Nonsurgical tissue diagnosis of thymic tumors can be made by transthoracic fine needle aspiration (TTFNA) or transthoracic core needle biopsy (TTCNB), conventional bronchoscopic biopsy procedures, endobronchial ultrasonography-guided transbronchial needle aspiration (EBUS-TBNA), endoscopic ultrasound-guided fine needle aspiration (EUS-FNA) or medical thoracoscopy (4-8).

\section{Surgical biopsy procedures}

If TTFNA or TTCNB cannot be performed or is not diagnostic, two approaches by open surgery can be used and both provide a diagnostic sensitivity of $\geq 90 \%$.

\section{For large and/or invasive thymic tumors, anterior mediastinotomy (Chamberlain procedure) is the procedure of choice (7-15)}

Video-assisted thoracic surgery (VATS) can also be utilized as a minimally invasive procedure for biopsy purposes but has the risk of pleural space seeding. Thus, VATS can be useful in cases already with pleural involvement. Mediastinoscopy is another minimally invasive procedure that has been increasingly used over the last 2 decades to obtain tissue for the diagnosis of advanced or invasive thymic tumors $(4,6)$.

For small solid tumors not amenable to TTFNA, TTCNB, total thymectomy is performed for both diagnosis and treatment (7-15) (Figure 1A,B,C)

Macroscopic, histologic and genetic analysis of the resected specimen is required to determine the following features of thymic tumors (9):

(I) The stage and resection status that can impact radiotherapy indication,

(II) The histological subtype that is relevant to prognosis and treatment,

(III) The mutational status of the thyrosine-protein kinase KIT (CD117) gene on exons 9, 11 and 14 in unresectable or refractory thymic carcinoma for treatment with tyrosine kinase inhibitors. New molecular targets are expected soon with the emerging next-generation sequencing.

\section{Nonsurgical biopsy procedures}

\section{Transthoracic fine needle aspiration}

Image-guided [ultrasound- or computed tomography (CT)-guided] TTFNA of a mediastinal mass is the least invasive technique that can be diagnostic in $50-82 \%$ of cases $(4,5,7,14)$. However, the sensitivity of cytologic aspirate is less than $60 \%$ in distinguishing thymic tumors from other subtypes. Furthermore, there might also be errors with TTFNA in subtyping thymomas due to tumor heterogeneity. Thus, the efficacy of TTFNA in the diagnosis of thymomas is controversial since histologic differentiation-particularly between thymomas, thymic carcinomas, lymphomas and thymic hyperplasia—can be 

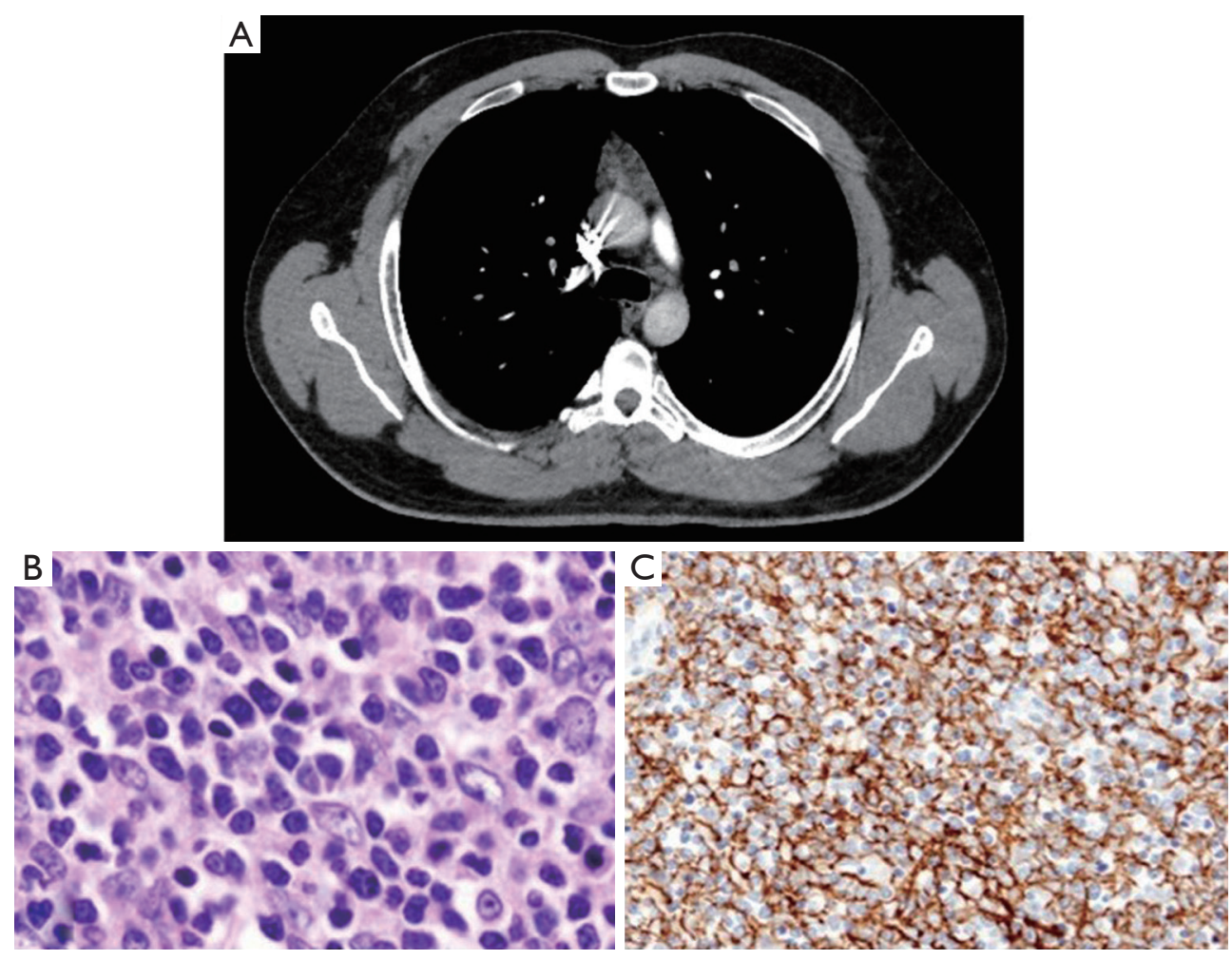

Figure 1 A case of thymoma with myastenia gravis diagnosed and treated by surgery. (A) Thoracic CT section showing noninvasive small mass in the anterior superior mediastinum; (B) histology of the tumor (hematoxylin \& eosin, $\times 100$ ): noninvasive thymoma (type B1); (C) immunostain (Cytokeratin CAM5.2, ×100): noninvasive thymoma (type B1).

problematic with the small tissue volume obtained by this method (Figure $2 A, B, C, D$ ). Furthermore, sufficient tissue sample for genetic marker studies (flow cytometry, etc.) is also required for optimal treatment of hematological malignancies $(5,7-9,16-19)$.

Some centers do not routinely perform TTFNA in tumors suspicious of thymoma because malignant cell seeding in the needle track is feared whereas major centers for thymoma surgery commonly perform the procedure without tumor seeding at biopsy site or needle tract $(5,16)$. In suspected thymomas and thymic tumors, the established recommendations for TTFNA technique and interpretation of the samples should be followed to improve the diagnostic yield (Table 1) $(7,17,20)$.

\section{Transthoracic core needle biopsy}

As a strategy to obtain larger specimens for histologic examination of thymic tumors and other mediastinal masses, ultrasound- or CT-guided TTCNB rather than TTFNA has been adopted in the recent years. TTCNB by ultrasound or CT guidance has higher sensitivity and specificity $(90-100 \%)$. Thus, it is superior to TTFNA with reduction in surgical diagnostic procedures and avoidance of repeat biopsy owing to nondiagnostic results (Figure $3 A, B, C, D, E$ ). Moreover, in thymic tumors good concordance (79\%) for the WHO classification has been reported between the diagnoses based on image-guided TTCNB and surgical specimens $(5,18,21-23)$. Performing TTCNB together with TTFNA can increase the accuracy in differentiating thymic tumors from other neoplasms, such as lymphomas and germ cell tumors (18,21,24-26).

\section{Conventional bronchoscopy}

Conventional bronchoscopic methods such as endobronchial biopsy (EBB), brushing, transbronchial biopsy (TBB) and/ or conventional transbronchial needle aspiration (c-TBNA) through rigid or flexible bronchoscope can be used to diagnose thymic tumors if the tumor invades or metastasizes into the airways, lung parenchyma, or mediastinal structures abutting the airways. 

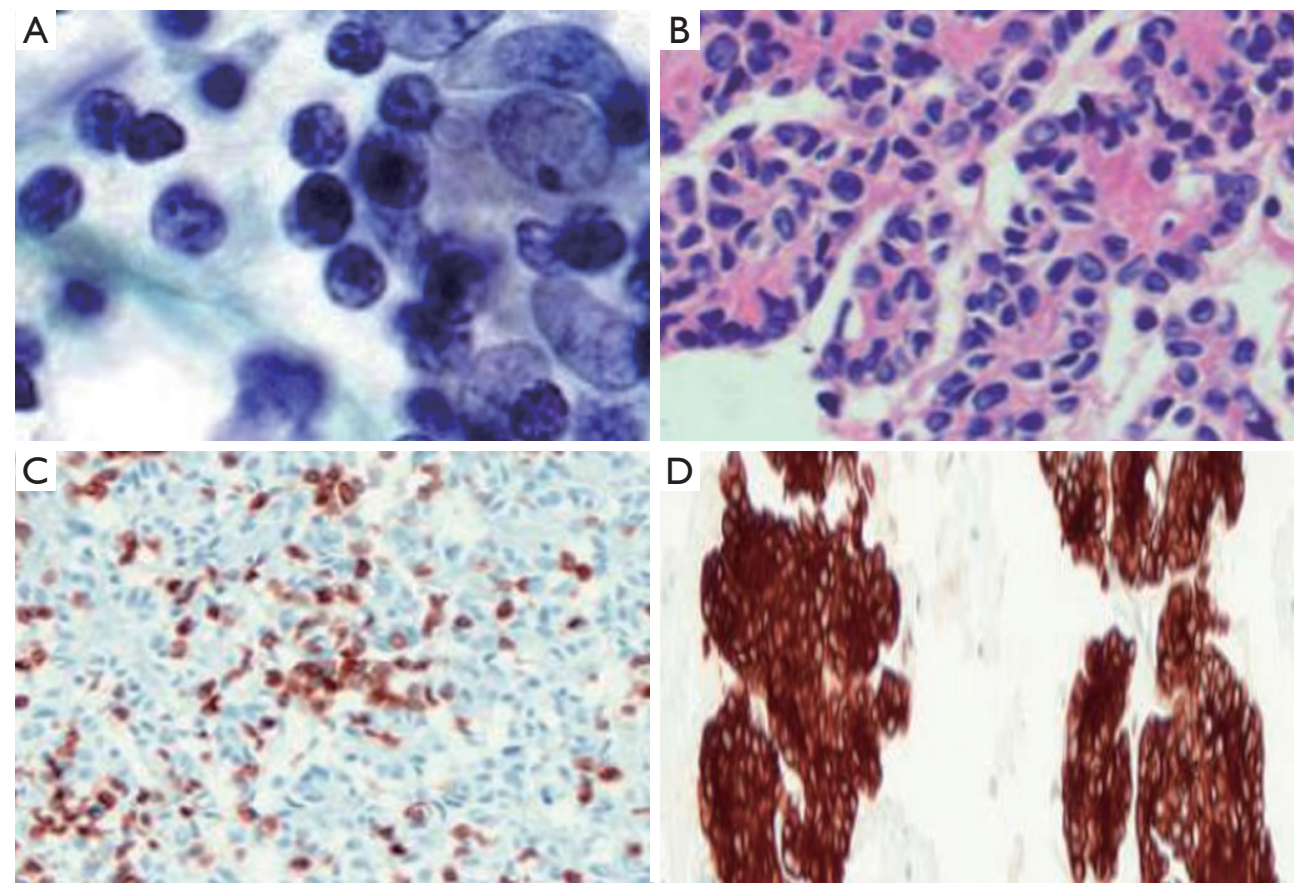

Figure 2 Transthoracic fine needle aspiration specimens from a thymoma (type A). The smear cytology is suggestive but not diagnostic for thymoma and cannot differentiate the subtypes. The diagnosis and subtype are confirmed by histopathologic and immunohistochemical examination of the cell blocks. (A) Smear cytology (papanicolaou, $\times 600$ ): dual population of lymphoid and epithelial cells; (B) cell block (hematoxylin \& eosin, $\times 100$ ): glandular structures and rosettes with no lumen; (C) cell block (CD3 immunostain, $\times 100)$ : scattered CD3positive lymphocytes; (D) cell block (cytokeratin immunostain, $\times 40$ ): keratin-positive epithelial cells.

Table 1 Recommendations for transthoracic fine needle aspiration of mediastinal lesions $(7,17,20)$

Technical recommendations

Needle gauge: $\geq 22$-gauge

Rapid onsite evaluation (ROSE) or $\geq 3$ needle passes

ROSE or $\geq 6$ smears ( 2 smears/needle pass)

Collection of aspirates as smears or liquid based preparations and cell blocks

An aspirate for flow cytometry (in high suspicion for lymphoma)

Recommendations for interpretation and reporting

Correlation with clinical and radiologic findings

Reporting specimen adequacy*

Utilization of immunohistochemistry according to the differential diagnosis

Consulting a second experienced pathologist in case of diagnostic difficulty

*, no established criteria exists for specimen adequacy; assessment should be according to differential diagnosis.

\section{Endobronchial biopsy}

Endobronchial lesions due to a thymoma or other thymic tumors have been reported to be rarely encountered; only 20 cases up to 2012 have been reported globally (27-31). Some of the endobronchial lesions not detected by imaging methods might have been missed as bronchoscopy is not the first-choice diagnostic procedure for thymic tumors. Whether the endobronchial lesions are hematogenous or lymphangitic metastases from thymic tumors is uncertain. There is a speculation that the tumor penetrates the parietal and visceral pleura and then lung parenchyma and finally invades a weak distal airway wall and grows toward a proximal site (mostly left upper lobe bronchus but also right upper lobe bronchus or trachea) as a polypoid lesion $(27,29,30)$.

In these cases with endobronchial lesions, EBB can be diagnostic but in most, biopsy specimens have been reported to be only normal bronchial mucosa or necrotic tissue. Taking multiple EBB samples (at least 3-5) and performing an immunohistochemical study are recommended to 


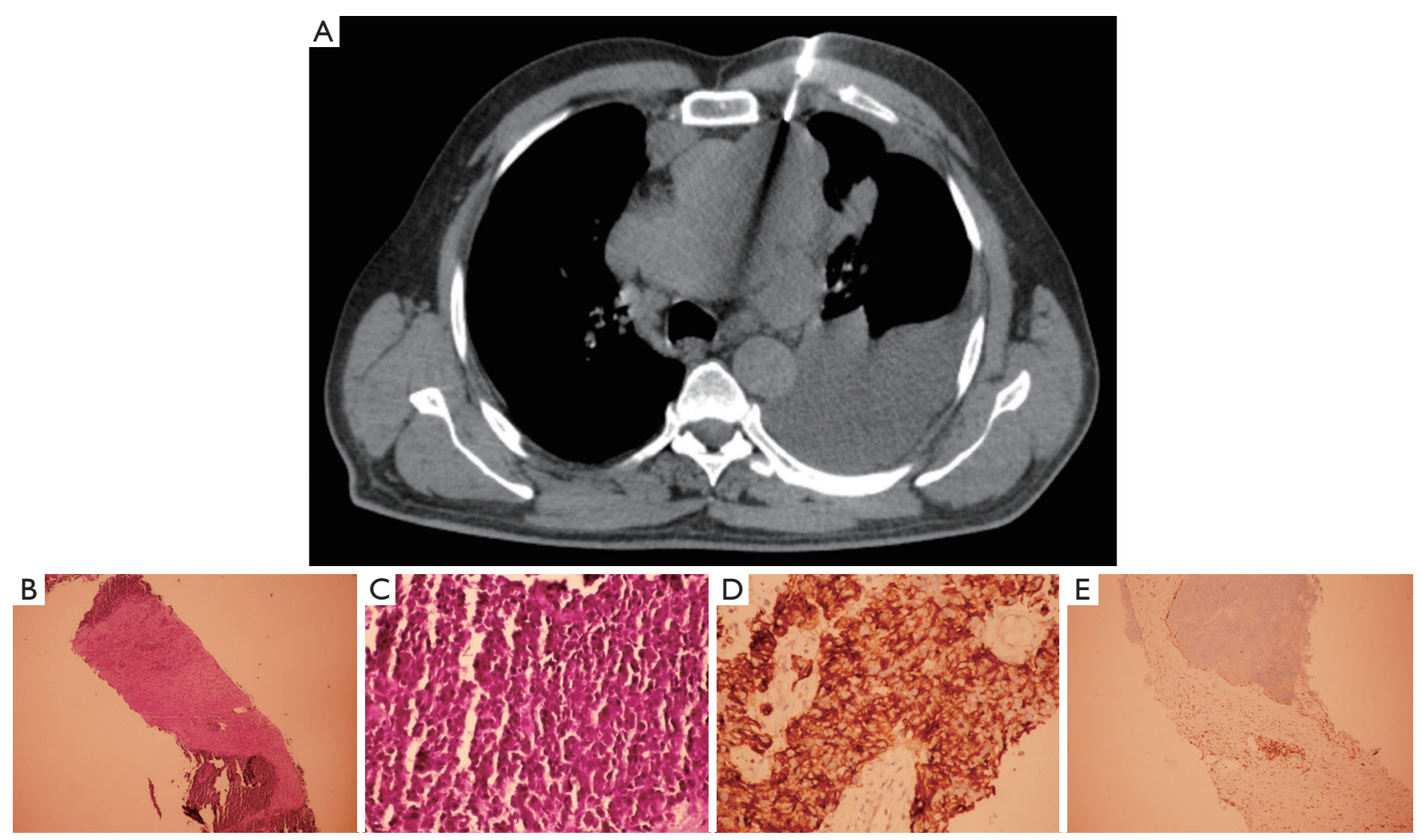

Figure 3 A case of thymic carcinoma (type B3) with extensive mediastional invasion and pleural effusion. (A) CT-guided transthoracic core needle biopsy procedure using Tru-cut needle, Tru-cut biopsy specimen: (B) tumor islands among connective tissue planes (hematoxylineosin, $\times 40$ ), (C) epithelial atypical cells (hematoxylin-eosin, $\times 100$ ), (D) specific "chicken wire" staining with pancytokeratin around the epithelial cells (immunohistochemistry, $\times 100$ ), (E) staining of lymphocytes with CD1a in tumor area and connective tissue stroma: positivity of lymphocytes (1mmunohistochemistry, $\times 100)$.

increase the diagnostic yield. Immunohistochemical study will show the admixture of epithelial cells and lymphocytes characteristic for thymoma [epithelial cells positive for cytokeratin (CK): CK5/6, CK7, CK10 and CK8, and immature T-cells positive for CD1a, CD4, CD8, CD5, CD99 and TdT] $(27,29,31)$.

\section{Brushing}

Brushing has been shown to diagnose thymoma (32) and thymic carcinoma (33) if the tumor invades into the airway lumen and causes an endobronchial lesion. However, there is a paucity of publications on the diagnostic yield of brushing in thymic tumors. Brushing, by itself, is not expected to have high yield $(63 \%)$ as it provides a small volume of cytological specimen that will not be sufficient to differentiate and subtype the tumor and perform genetic marker studies. If combined with EBB, it can increase the diagnostic yield by $18 \%$ (33).

\section{Transbronchial biopsy}

Hematogeneous metastasis to lung occurs in thymomas $(0-8 \%)$ and thymic carcinomas (59\%). Most of these metastases have nodular pattern $(34,35)$. Fluoroscopy-, radial-probe EBUS- or navigational bronchoscopy-guided TBB can be used to sample these nodules. TBB can also be utilized if there are infiltrative pulmonary metastases with miliary or lymphangitic pattern. In Pubmed and Google search there is no article on or related to TBB in cases with thymoma or other thymic tumors.

\section{Conventional transbronchial needle aspiration}

Although there are several articles on EBUS-TBNA in the diagnosis of thymic tumors, only one study (36) and a congress abstract (37) have been found on c-TBNA and thymic tumors in the Google or Pubmed search. The diagnostic yield of c-TBNA in thymomas was reported as $50 \%(2 / 4)$ in the above-mentioned study (36). The 
congress abstract is on the diagnosis of a large ectopic intrapulmonary thymoma by c-TBNA performed through the compressed bronchial wall in the middle lobe. The histology of the resected tumor was found to be consistent with thymoma corroborating c-TBNA result (37).

In the diagnosis of thymoma and thymic tumors, c-TBNA can be useful in the following situations provided that primary tumor or its metastasis is abutting the airway wall:

* Invasive mediastinal tumor,

* Mediastinal or hilar lymph node metastasis,

* Intrapulmonary metastasis,

* Ectopic intrapulmonary tumor.

In case of a peripheral intrapulmonary metastasis or ectopic intrapulmonary tumor in the inner or middle one third of the lung, c-TBNA should be performed using the guidance of fluoroscopy, radial-probe EBUS or navigational bronchoscopy (38-40).

As in TTFNA, to increase the diagnostic yield, smears or liquid based cytology preparations and cell blocks should be combined when sending c-TBNA specimens for pathologic evaluation $(39,41)$.

\section{Endobronchial ultrasound-guided transbronchial needle aspiration}

EBUS-TBNA provides minimally invasive approach for diagnosing mediastinal tumors including thymomas and other thymic tumors (36,42-46). The diagnostic yield of this technique in mediastinal masses has been shown to be up to $93 \%$ (87\% in malignant and $96 \%$ in benign masses) (42).

Most of the articles on EBUS-TBNA in thymic tumors are case reports (44-46). There are only few studies $(6,36)$ owing to the rarity and anterior mediastinal location of thymic tumors not usually accessible by this procedure. However, there has been a significant increase in the use of EBUS-TBNA and other minimally invasive procedures as compared to open biopsy in the last two decades (6).

EBUS-TBNA indications are similar to those of c-TBNA in thymic tumors: invasive mediastinal tumor, mediastinal or hilar lymph node metastasis, intrapulmonary metastasis or ectopic intrapulmonary tumor adjacent to or compressing bronchi or trachea. The diagnostic yield of EBUS-TBNA was shown to be $75 \%(3 / 4)$ in a study comparing c-TBNA, EBUS-TBNA and EBUS-guided miniforceps biopsy (36).

\section{Endoscopic ultrasound-guided fine needle aspiration}

EUS-FNA has also been used in the diagnosis of thymic tumors. However, the related publications are case reports and small number of cases in some studies as mentioned above for conventional bronchoscopic procedures and EBUS-TBNA (47-50).

EUS-FNA can sample and diagnose thymomas or other thymic tumors ectopically located or recurring in the posterior mediastinum $(49,50)$ as well as those in the anterior and superior mediastinum (47) provided that the tumor has a part adjacent to the esophageal wall.

In a pilot study on the diagnostic yield of EUS-FNA using 22-gauge needle in abdominal and mediastinal solid masses, continuous high negative pressure suction with a $60 \mathrm{~mL}$ syringe was compared with standard negative pressure suction with a $10 \mathrm{~mL}$ syringe. The diagnostic accuracy of each method was $76.9 \%$ and increased to $84.6 \%$ when they were combined. However, EUS-FNA with continuous high pressure suction could obtain tissue samples for histologic examination in $96 \%$ of the cases including a malignant thymoma whereas the standard method obtained cytologic specimens in all cases and could not diagnose the malignant thymoma. Furthermore, only one needle pass was performed during high pressure suction and 5 passes during standard pressure suction (48).

Using a 19-gauge needle (50) and/or continuous high pressure suction (48) during EUS-FNA obtains histologic specimens and is likely to be more diagnostic than using 22 -gauge needle and/or standard pressure suction in thymic tumors. Further studies have to be conducted to confirm the effect of needle gauge, high pressure suction and number of needle passes on the diagnostic yield of EUS-FNA in thymic tumors.

\section{Medical thoracoscopy}

Rigid or flexi-rigid medical thoracoscopy or pleuroscopy is a minimally invasive procedure allowing for pleural biopsy under direct visualization and for therapeutic interventions (chemical pleurodesis and placement of indwelling tunneled pleural catheter) in the pleural space (51-55).

Medical thoracoscopy is not a standard diagnostic option for thymic tumors. As in VATS, there is a risk of pleural seeding during medical thoracoscopy. Thus, it has no place in diagnosis or treatment of noninvasive thymic tumors amenable to surgery. It can be performed if clinically and radiographically suspected thymoma or other thymic tumor is not amenable to surgical resection owing to its locally advanced stage and pleural involvement (invasion into pleural space, pleural effusion or metastasis to pleura) 
(6,56-58).

In PubMed or Google search, no article has been found particularly on the diagnosis of thymic tumors using medical thoracoscopy. Instead, small number of thymic tumors diagnosed by this method can be found in the mostly retrospective studies on diagnosis and treatment of mediastinal tumors by thoracoscopy (59) or on medical thoracoscopy in the management of undiagnosed pleural effusions (60). Over the last two decades, besides other minimally invasive procedures such as EBUS-TBNA, EUSFNA and mediastinoscopy, the upward trend in the use of medical thoracoscopy for the pretreatment diagnosis of locally advanced thymic tumors is noteworthy (6).

\section{Recommendations for increasing adequacy and accuracy of diagnostic specimens}

The following criteria will be beneficial in improving the adequacy and accuracy of the specimens obtained by the diagnostic procedures and consequently in optimizing the management of TTs:

(I) Obtaining histologic specimens rather than cytologic ones whenever amenable,

(II) Combining smears or liquid based cytology preparations and cell blocks when obtaining cytologic specimens,

(III) Obtaining multiple ( $\geq 3-6$ ) sufficient cytologic or histologic samples,

(IV) Combining histologic and cytologic specimens when possible,

(V) Performing morphologic, immunohistochemical and molecular analyses on all histologic and cytologic specimens,

(VI) Using ROSE for cytologic specimens if it is available,

(VII) Correlating pathologic findings with clinical and radiologic findings,

(VIII) Working with and consulting experienced pathologists.

\section{Acknowledgments}

Funding: None.

\section{Footnote}

Provenance and Peer Review: This article was commissioned by the editorial office, Fournal of Thoracic Disease for the series "Thymoma". The article has undergone external peer review.

Conflicts of Interest: The author has completed the ICMJE uniform disclosure form (available at: http://dx.doi. org/10.21037/jtd-2019-thym-14). The series "Thymoma" was commissioned by the editorial office without any funding or sponsorship. SB served as an unpaid Guest Editor of the series. The author has no other conflicts of interest to declare.

Ethical Statement: The author is accountable for all aspects of the work in ensuring that questions related to the accuracy or integrity of any part of the work are appropriately investigated and resolved.

Open Access Statement: This is an Open Access article distributed in accordance with the Creative Commons Attribution-NonCommercial-NoDerivs 4.0 International License (CC BY-NC-ND 4.0), which permits the noncommercial replication and distribution of the article with the strict proviso that no changes or edits are made and the original work is properly cited (including links to both the formal publication through the relevant DOI and the license). See: https://creativecommons.org/licenses/by-nc-nd/4.0/.

\section{References}

1. Tseng YC, Tseng YH, Kao HL, et al. Long term oncological outcome of thymoma and thymic carcinomaan analysis of 235 cases from a single institution. PLoS One 2017;12:e0179527.

2. Engels EA, Pfeiffer RM. Malignant thymoma in the United States: demographic patterns in incidence and associations with subsequent malignancies. Int J Cancer 2003;105:546-51.

3. Hung YS, Chang CL, Chang H, et al. Thymoma. J Intern Med Taiwan 2009;20:344-51.

4. Sperling B, Marschall J, Kennedy R, et al. Thymoma: a review of the clinical and pathological findings in 65 cases. Can J Surg 2003;46:37-42.

5. Tomaszek S, Wigle DA, Keshavjee S. Thymomas: review of current clinical practice. Ann Thorac Surg 2009;87:1973-80.

6. Yue J, Gu Z, Yu Z, et al. Members of the Chinese Alliance for Research in Thymomas. Pretreatment biopsy for histological diagnosis and induction therapy in thymic tumors. J Thorac Dis 2016;8:656-64. 
7. Detterbeck FC, Zeeshan A. Thymoma: current diagnosis and treatment. Chin Med J 2013;126:2186-91.

8. Scorsetti M, Leo F, Trama A, et al. Thymoma and thymic carcinomas. Crit Rev Oncol Hematol 2016;99:332-50.

9. Ried M, Marx A, Götz A, et al. State of the art: diagnostic tools and innovative therapies for treatment of advanced thymoma and thymic carcinoma. Eur J Cardiothorac Surg 2016;49:1545-52.

10. Travis WD. The 2015 WHO classification of lung tumors. Pathologe 2014;35 Suppl 2:188.

11. Mehran R, Ghosh R, Maziak D, et al. Surgical treatment of thymoma. Can J Surg 2002;45:25-30.

12. Murakawa T, Nakajima J, Kohno T, et al. Results from surgical treatment for thymoma. 43 years of experience. Jpn J Thorac Cardiovasc Surg 2000;48:89-95.

13. Rendina EA, Venuta F, Martelli M, et al. Successful resection of a thymoma in an elderly patient. Ital J Surg Sci 1988;18:79-82.

14. Herman SJ, Holub RV, Weisbrod G, et al. Anterior mediastinal masses: utility of transthoracic needle biopsy. Radiology 1991;180:167-70.

15. Moore KH, McKenzie PR, Kennedy C, et al. Thymoma: trends over time. Ann Thorac Surg 2001;72:203-7.

16. Detterbeck FC. Does an anecdote substantiate dogma? Ann Thorac Surg 2006;81:1182; author reply 1182-83.

17. Marchevsky A, Marx A, Ströbel P, et al. Policies and reporting guidelines for small biopsy specimens of mediastinal masses. J Thorac Oncol 2011;6:S1724-9.

18. Mueller DK. Thymic tumors. Mancini MC, editor. EMedicine: Medscape; [updated February 7; cited 2020 March 30]. Available online: https://emedicine.medscape. com/article/427197-overview

19. Assaad MW, Pantanowitz L, Otis CN. Diagnostic accuracy of image-guided percutaneous fine needle aspiration biopsy of the mediastinum. Diagn Cytopathol 2007;35:705-9.

20. Ali SZ, Erozan YS. Thymoma. Cytopathologic features and differential diagnosis on fine needle aspiration. Acta Cytologica 1998;42:845-54.

21. Annessi V, Paci M, De Franco S, et al. Diagnosis of anterior mediastinal masses with ultrasonically guided core needle biopsy. Chir Ital 2003;55:379-84.

22. Morrissey B, Adams H, Gibbs AR, et al. Percutaneous needle biopsy of the mediastinum: review of 94 procedures. Thorax 1993;48:632-37.

23. Yonemori K, Tsuta K, Tateishi U, et al. Diagnostic accuracy of CT-guided percutaneous cutting needle biopsy for thymic tumours. Clin Radiol 2006;61:771-5.

24. Nasit JG, Patel M, Parikh B, et al. Anterior mediastinal masses: a study of 50 cases by fine needle aspiration cytology and core needle biopsy as a diagnostic procedure. South Asian J Cancer 2013;2:7-13.

25. Zhou JH, Shan HB, Ou W, et al. Contrast-enhanced ultrasound improves the pathological outcomes of US-guided core needle biopsy that targets the viable area of anterior mediastinal masses. Biomed Res Int 2018;2018:9825709.

26. Greif J, Staroselsky AN, Gernjac M, et al. Percutaneous core needle biopsy in the diagnosis of mediastinal tumors. Lung Cancer 1999;25:169-73.

27. Sakuraba M, Sagara Y, Tamura A, et al. A case of invasive thymoma with endobronchial growth. Ann Thorac Cardiovasc Surg 2005;11:114-6.

28. Abiko M, Sato T, Shiono S, et al. A case of invasive thymoma displaying endobronchial extension. Kikansigaku (J Jpn Soci Bronch) 1999;21:289-93.

29. Nagamata M, Okuma Y, Hosomi Y, et al. Thymic carcinoma with endobronchial metastasis: a case report. J Bronchology Interv Pulmonol 2017;24:159-62.

30. Honda T, Hayasaka M, Hachiya T, et al. Invasive thymoma with hypogammaglobulinemia spreading within the bronchial lumen. Respiration 1995;62:294-6.

31. Hwang JT, Kim MH, Chang KJ. A case of invasive thymoma with endotracheal polypoid growth. Tuberc Respir Dis (Seoul) 2012;73:331-5.

32. Shimosato Y, Mukai K, Matsuno Y. Thymoma. In: Silverberg SG, Gardner WA, Sobin LH, editors. Tumors of the mediastinum. AFIB atlas of tumor pathology. Maryland: ARP Press Silver Spring; 2010:79-80, 83.

33. Ikemura K, Lin DM, Martyn CP, et al. Endobronchial metastasis from extrapulmonary neoplasms: analysis of clinicopathologic features and cytological evaluation by bronchial brushing. Lung 2017;195:595-9.

34. Hirono M, Nonaka M, Himuro N. Two cases of thymoma with pulmonary metastasis: a case report. World J Surg Oncol 2014;12:114.

35. Kondo K, Monden Y. Lymphogenous and hematogenous metastasis of thymic epithelial tumors. Ann Thorac Surg 2003;76:1859-64.

36. Herth FJF, Morgan RK, Eberhardt R, et al. Endobronchial ultrasound-guided miniforceps biopsy in the biopsy of subcarinal masses in patients with low likelihood of nonsmall cell lung cancer. Ann Thorac Surg 2008;85:1874-8.

37. Davis-McDonald K, Abu Dayah I. A case of giant intrapulmonary thymoma. Chest Annual Meeting, San Antonio, Texas, October 6-10, 2018 (Abstract).

38. Bilaceroglu S, Chhajed P. Transbronchial needle 
aspiration: a diagnostic tool in routine bronchoscopy. J Assoc Physicians India 2005;53:797-802.

39. Minai OA, Mehta AC. Bronchoscopy: Transbronchial needle aspiration. Feller-Kopman DJ, editor. UpToDate [updated 2020 Jan 28; cited 2020 March 30]. Available online: https://www.uptodate.com/contents/ bronchoscopy-transbronchial-needle-aspiration

40. Mondoni M, Sotgiu G, Bonifazi M, et al. Transbronchial needle aspiration in peripheral pulmonary lesions: a systematic review and meta-analysis. Eur Respir J 2016;48:196-204.

41. van der Heijden EHFM, Casal RF, Trisolini R, et al. Guideline for the acquisition and preparation of conventional and endobronchial ultrasound-guided transbronchial needle aspiration specimens for the diagnosis and molecular testing of patients with known or suspected lung cancer. Respiration 2014;88:500-17.

42. Yasufuku K, Nakajima T, Fujiwara T, et al. Utility of endobronchial ultrasound-guided transbronchial needle aspiration in the diagnosis of mediastinal masses of unknown etiology. Ann Thorac Surg 2011;91:831-6.

43. Figueiredo VR, Jacomelli M, Rodrigues AJ, et al. Current status and clinical applicability of endobronchial ultrasound-guided transbronchial needle aspiration. J Bras Pneumol 2013;39:226-37.

44. Moonim MT, Breen R, Gill-Barman B, et al. Diagnosis and subclassification of thymoma by minimally invasive fine needle aspiration directed by endobronchial ultrasound: a review and discussion of four cases. Cytopathology 2012;23:220-8.

45. Yoshida Y, Singyoji M, Ashinuma H, et al. Successful Diagnosis of a Thymoma by Endobronchial Ultrasoundguided Transbronchial Needle Aspiration: A Report of Two Cases. Intern Med 2015;54:2735-9.

46. Yajima T, Mogi A, Shimizu K, et al. Ectopic thymoma in the paratracheal region of the middle mediastinum: a rare case report and literature review. BMC Res Notes 2018;11:256.

47. Gupta R. Thymolipoma in child: a case diagnosed by correlation of ultrasound-guided fine needle aspiration (EUS-FNA) cytology and computed tomography with histological confirmation. Cytopathology 2014;25:278-9.

48. Larghi A, Noffsinger A, Dye CE, et al. EUS-guided fine needle tissue acquisition by using high negative pressure suction for the evaluation of solid masses: a pilot study.
Gastrointest Endosc 2005;62:768-74.

49. Holt BA, Varadarajulu S, Krall K, et al. Unusual case of a stage I thymoma of the posterior mediastinum: endoscopic ultrasound-guided fine needle aspiration alone clinches the diagnosis. Endoscopy 2014;46:E577-8.

50. Larghi A, Rodriguez-Wulff E, Noffsinger A, et al. Recurrent malignant thymoma diagnosed by EUS-guided Trucut biopsy. Gastrointest Endosc 2006;63:859-60.

51. Lee H. Medical thoracoscopy (pleuroscopy): Diagnostic and therapeutic applications. Broaddus VC, Feller-Kopman DJ, editors. Up'ToDate [updated 2019 Aug 21; cited 2020 March 30]. Available online: https://www.uptodate.com/ contents/medical-thoracoscopy-pleuroscopy-diagnosticand-therapeutic-applications/print

52. Yap KH, Phillips MJ, Lee YCG. Medical thoracoscopy: Rigid thoracoscopy or flexi-rigid pleuroscopy? Curr Opin Pulm Med 2014;20:358-65.

53. Lee P, Colt HG. State of the Art: Pleuroscopy. J Thorac Oncol 2007;2:663-70.

54. Murthy V, Bessich JL. Medical thoracoscopy and its evolving role in the diagnosis and treatment of pleural disease. J Thorac Dis 2017;9:S1011-21.

55. Loddenkemper R, Mathur PN, Lee P, et al. History and clinical use of thoracoscopy/pleuroscopy in respiratory medicine. Breathe 2011;8:145-55.

56. Padda SK, Keijzers M, Wakelee HA. Pretreatment biopsy for thymic epithelial tumors-Does histology subtype matter for treatment strategy? J Thorac Dis 2016;8:1895-900.

57. National Comprehensive Cancer Network. Thymomas and Thymic Carcinomas 2016; (version 1. 2016).

58. Girard N, Ruffini E, Marx A, et al. Thymic epithelial tumours: ESMO Clinical Practice Guidelines for diagnosis, treatment and follow-up. Ann Oncol 2015;26 Suppl 5:v40-55.

59. Cirino LM, Milanez de Campos RJ, Fernandez A. Diagnosis and treatment of mediastinal tumors by thoracoscopy. Chest 2000;117:1787-92.

60. Halima KM, Makled SF, Ali SM, et al. Six years experience of medical thoracoscopy at Al Hussein University Hospital. Egypt J Chest Dis Tuberc 2017;66:175-9.

Cite this article as: Bilaçeroğlu S. How to obtain adequate biopsy specimen in suspected thymic tumors. J Thorac Dis 2020;12(12):7598-7606. doi: 10.21037/jtd-2019-thym-14 